\title{
Language, Experience and Professional Learning (What Walter Benjamin Can Teach Us)
}

\author{
Brenton Doecke $^{a *}$ and Iris Susana Pires Pereira ${ }^{b}$ \\ ${ }^{a}$ School of Education, Deakin University, Melbourne, Australia; ${ }^{b}$ Institute of Education, \\ University of Minho, Braga, Portugal
}

\begin{abstract}
This essay raises questions about how language educators might construct and further develop their epistemology of practice in and through the situations in which they work from day to day. The occasion for this paper is our work as guest editors of a special issue of L-1: Educational Studies in Language and Literature, when we invited L1 teachers to reflect on the role that language plays in their professional learning, whether it be in the form of conversations with peers, reflective writing, or by other means. We begin this essay by locating our reflections within our current policy context, namely the standards-based reforms that have come to dominate educational thinking around the world, offering a brief critique of the values and attitudes embedded within them. We then outline a philosophical framework as an alternative to the world-view reflected by such reforms, focusing specifically on the work of Walter Benjamin. In the final sections, we review our work as guest editors of the special issue of $L-1$, reflecting on what we have learned from the papers we have assembled for this issue, and locating our learning within the philosophical framework that we have drawn from Benjamin. We argue that it is timely for language educators to articulate the assumptions that inhere within their work, in contradistinction to the common sense embedded in standards. Thus we might begin to reconceptualise the relation between language, experience and professional learning in opposition to the hegemony of standards.
\end{abstract}

Keywords: language education; experience; professional learning; epistemology of practice; standards-based reforms

\section{i}

Educational policy pronouncements typically feature altruistic statements about the need to lift children out of poverty in order that everyone can find a place in a twenty-first century economy. The most famous instance is 'No Child Left Behind' in the United States; but other countries have generated equally interesting policy statements of this kind. Australia, for example, has recently witnessed the publication of the 'Melbourne Declaration on Education Goals for Young Australians', which appropriates the language of social justice in order to affirm 'the central role of education in building a democratic, equitable and just society' (Ministerial Council on Education, Employment, Training and Youth Affairs (MCEETYA) 2008, 4). Glance through this document, however, and you find that social justice and inclusion are conceived entirely on the terms of those who deem themselves to be in a

*Corresponding author. Email: brenton-doecke@deakin.edu.au 
position to offer this dispensation. A key means of guaranteeing that schools are operating in a socially just and inclusive way, according to the Declaration, is by ensuring that they focus on 'improving performance and student outcomes', providing Governments with 'good quality data' that will enable them to 'analyse how well schools are performing' (MCEETYA 2008, 16). In Australia this has meant mandated literacy testing for students in all school sectors across primary and secondary education, and the publication of students' results on the 'My School' website (http://www.myschool.edu.au/). These results supposedly put parents in a position to make the right choice of school for their children. Yet the question goes begging as to how such tests construct 'literacy'. This remains the province of the 'measurement experts', who devise the tests and guarantee the validity of the results (http://www.nap.edu.au/About/ACARAs_expertise/index.html). Rather than offering any defensible concept of 'literacy', these 'measurement experts' simply count it. They are in thrall to numbers that represent life as it is lived in schools only in the most partial or indeed distorted way.

We are invoking the world of standards-based reforms (Darling-Hammond 2004) because we want to begin this essay by foregrounding an absence that lies at their heart, namely the voices of those whom such policies supposedly serve, the young people who are in danger of being 'left behind'. The policy statements that we have been considering systematically bracket out any trace of the experiences of young people who are the objects of those statements. The phrase, "no child left behind', fails to be ethically responsive to that mass of children whose life experiences remain outside the ken of corporate society. Indeed, it erases any recognition of those others. What, after all, is the referent of 'no child'? To be ethically responsive means being sensitive to others, indeed acknowledging that the existence of other people exceeds any claim that we might make to comprehend them (cf. Critchley 1992/1999, 284). Such recognition fractures any notion of a 'self' or subjectivity that is complacently at one with itself, as though what 'I' and other likeminded people think and feel defines the scope of human experience. It means accepting how 'I' am 'exposed' or 'vulnerable' in the presence of others, a being amongst other beings 'of flesh and blood' (Levinas 1981/2004, 77, 74). 'Flesh and blood' individuals, however, are precisely what are missing from the statistical data amassed by high stakes testing (cf. Koretz 2008).

Young people are constructed in an equally problematical way in the Australian policy statement to which we have referred. The Melbourne Declaration is a declaration of educational goals 'for' young Australians, and it does not for a moment attempt to tap into the aspirations of Australia's youth as they might give voice to them. The term 'young people' in the Melbourne Declaration is an empty space to be filled with 'the knowledge, understanding, skills and values' that are necessary for successful participation in a twenty-first century globalizing economy (MCEETYA 2008, 4). Their subjectivities are to be fashioned according to the designs of government, thus 'ensuring the nation's ongoing economic prosperity and social cohesion' $(2008,4)$. That such policies are bereft of any recognition of the lifeworlds of young people who are their target was made startlingly clear when the then-Federal Education Minister (now Prime Minister) accused those who were objecting to the likely consequences of publishing school tests results of wanting to produce 'happy, illiterate ... children' (Bita 2009). State schools around Australia have increasingly been obliged to direct their efforts towards realizing the unstated alternative - unhappy, literate children - devoting whole blocks of time to drilling 
and skilling in order to improve the test scores of their students (see Comber and Cormack 2011; Doecke, Kostogriz, and Illesca 2010). A telling instance of this development is a book that has recently been commended by the Chair of the Australian Curriculum, Assessment and Reporting Authority (ACARA) (McGaw 2011, viii), which reports on 'a strategy for systemic educational improvement' implemented in the Northern Metropolitan Region in Melbourne, an area catering for some of the most socially disadvantaged communities in Victoria, in which the authors give an account of the remarkable improvement in performance they have achieved through strategies such as 'high reliability literacy teaching procedures', 'effective pedagogy' and 'the developmental management approach to classroom behaviour' (Hopkins, Munro, and Craig 2011). The language throughout the book comprises generalizations about students and schools without at any point conveying a sense of the individual lives and settings that have been touched by those reforms, an impression compounded by the fact that the chapter which supposedly tells the 'performance story' consists solely of graphs presenting standardized test scores. The book is symptomatic of the emerging hegemony of educational policies and practices, that will not even concede to young people 'the brief years of youth' - those 'serious and grim' policies imposed by neo-liberal governments obsessed by so-called 'improvement', that push young people 'directly into life's drudgery' (Benjamin 1996/2004, 3).

\section{ii}

The language that we have just borrowed is taken from an early essay written by Walter Benjamin for Der Anfang (The Beginning), a mouthpiece for the school reform movement led by Gustav Wyneken in Wilheminian Germany (Kramer 2003, 14; Leslie 2007, 20-30; Beasley-Murray 2007, 73). Of all the writers and theorists on whom we are drawing in order to articulate a standpoint with respect to language, experience and professional learning, it is perhaps Benjamin who most clearly defines the compass of our reflections. And this is not simply because of his disdain for those 'pedagogues whose bitterness will not even concede to us the brief years of youth', who 'serious and grim ... want to push us directly into life's drudgery ... devalue (ing) and destroy(ing) our years' (Benjamin 1996/2004, 3). His writing reflects an abiding preoccupation with the way young people make sense of the world in which they find themselves, spanning the essay from which we have just quoted to work he produced in the 1920s and 1930s. One Way Street, for example, contains the following attempt to capture a child's experience of the world, in contrast to the way 'pedagogues' prescribe materials that are supposedly suitable for children:

...the world is full of the most unrivalled objects for children's attention and use. And the most specific. For children are particularly fond of haunting any site where things are being visibly worked on. They are irresistibly drawn by the detritus generated by building, gardening, housework, tailoring or carpentry. In waste products they recognize the face that the world of things turns directly and solely to them. In using these things, they do not so much imitate the world of adults as bring together, in the artifact produced in play, materials of widely differing kinds in a new, intuitive relationship. Children thus produce their own small world of things within the greater one. The norms of this small world must be kept in mind if one wishes to create things specially for children, rather than let one's adult activity, through its requisites and instruments, find its own way to them. (Benjamin 1996/2004, 449-50) 
This passage occurs in a text comprising a heterogeneous collection of impressions of life in Germany immediately after the Great War. Although Benjamin is imagining the way children make meaning from the disparate objects they encounter, emphasizing the uniqueness of a child's experience of the world ('In Abfallprodukten erkennen sie das Gesicht, das die Dingwelt gerade ihnen, ihnen allein, zukehrt'; Benjamin 1928/1955, 22), this passage might also be read as a figure for how people continue to interpret phenomena around them, despite the fact that they may have grown into adulthood and even taken on the role of the life-denying 'pedagogues' whom Benjamin despised (cf. Doecke and McClenaghan 2011, 95). People continue actively to engage with the world, subjectively making sense of all that is presented to them. This is so, even when they pretend to posit the world as an object that lends itself to the most dispassionate scientific analysis, such as when 'measurement experts' construct the language and learning that children experience at school in the form of standardized test results or reduce the social life enacted in schools each day to a list of factors that they can count. Rather than being an 'objective' representation of young people's language and learning, psychometric exercises of this kind reflect a world view of the most partial kind, intervening in the world in an attempt to promote established interests.

The impulse behind Benjamin's writing is always to resist the force of habit and convention in order to see the world anew. His recognition of the potential of Brecht's 'Verfremdungseffekt' as enabling people to entertain alternative ways of seeing and thinking that might otherwise lie dormant in their everyday lives is an example of this reflexive disposition (Benjamin 1973; cf. Kramer 2003, 77). Benjamin found this capacity within himself, as he set about the task of writing about his childhood in Berlin at the turn of the century at the moment of reconciling himself to the life of an exile. Needless to say, Berlin Childhood around 1900 is anything but a maudlin exercise in nostalgia. The vignettes that make up this volume are premised on a recognition of the 'irretrievability' of the past. They constitute an attempt by Benjamin to explore the formation of his sensibility as a child, specifically 'to get hold of the images in which the experience of the big city is precipitated in a child of the middle class' (Benjamin 2002, 344). Benjamin's insights into how as a child he experienced the world nonetheless provide a source of hope for believing in the possibility of developing other forms of consciousness and being than those that prevail at present.

Children's creativity is evident in the language games they play. Repeatedly in Berlin Childhood around 1900, Benjamin recalls how as a child he coined new words, sometimes through association - he conflated the name of the street on which his aunt lived (Steglitzer Strasse) with 'Stieglitz', the word for goldfinch: 'And didn't my good aunt live in her cage like a talking bird?' (Benjamin 2002, 358). He also recalls how words were combined to make new meaning: 'First of all, one must not suppose that the covered market was called the Markt-Halle. No, it was pronounced Mark-Thalle. And just as these two words, in the customary use of language, were so worn out that neither retained its original sense, so, in my customary passage through that hall, all the images it afforded had so decayed that none of them spoke to the original concept of buying and selling...' (361). The child wanders through a space where 'slow-moving market women were enthroned', 'purveyors of all fruits of the field and orchard, all edible birds, fishes, and mammals', communicating 'with one another from stall to stall, whether by a flash of their great shiny buttons, by a smack on their aprons, or by a bosom-swelling sigh...' (362). 
All these passages convey a sense of the creative work that children perform with language, when they use words not simply to name the things of the world or to convey information about it, but as a vital means of engaging with the people and things around them (cf. Kramer 2003, 32-3). Words do not simply name objects, but embody a play between 'self' and the people with whom you share this world. And part and parcel of this play is a capacity for imagining the world differently, rather than remaining confined within the world as adults name it. Benjamin mentions 'an old nursery rhyme that tells of Muhme Rehlen'. He recalls that because the word 'Muhme' (an archaic word for aunt) meant nothing to him, 'this creature became for me a spirit: the mummerehlen' (390): 'The misunderstanding disarranged the world for me. But in a good way: it lit up paths to the world's interior' (390). He goes on to remark: 'If, in this way, I distorted both myself and the word, I did only what I had to do to gain a foothold in life' (390)

These meditations on language refer not only to a phase in the growth of children that might eventually be superseded and combined within a more mature stance vis-à-vis the world. We live our lives in forgetfulness, evading any insights that might disturb our sense of the way things are. By foregrounding language as a condition for our engagement with the world, Benjamin disrupts common sense assumptions, opening up dimensions of experience that exceed the everyday world of habits and customs that we follow without thinking.

Benjamin's sensitivity to the role that language plays in mediating our experiences and relationships with others is also evident in his privileging of narrative, which figures in his work as an alternative way of knowing to the reified forms of knowledge enshrined in science and technology (cf. Beasley-Murray 2007). Storytelling transcends the antinomies of subject and object, for it is always a social event, made possible through the language that people share, and anchored in the world that they have in common. Throughout Berlin Childhood around 1900, Benjamin recalls the stories and verses of his childhood as moments in his emerging sensibility. These are never presented simply as received tradition, but as stories that he appropriated and transformed in response to the people and life around him. We have already mentioned the 'Muhme Rehlen'. Other vignettes feature the little Hunchback, Sleeping Beauty, Snow White - all presences in the child's experience of his home and the life around him. To recall those stories is not simply to engage in reminiscence. A challenge for Benjamin becomes the place of storytelling in a world where the enormity of events defies the capacity of people to understand their experiences through giving shape to them in the form of narrative. His essay, 'The Storyteller', posits a world where technology and modern warfare have dwarfed human beings, who are reduced to crouching for shelter beneath a sky full of bombs (Benjamin 2002, 144). The industrial and technical achievements of the contemporary world, and the forms of technical rationality that have emerged to support its workings, undermine the role of language and narrative in embodying experience. The language that befits the contemporary world is a technical language that is limited to describing how things function, just as the jargon employed by psycho-metricians describes what children can do, rather than what they are potentially capable of achieving. The focus is relentlessly on what 'is' rather than on what might be, on a world conceived in the most jejune terms rather than a world that we are constantly re-making each day. Yet, as Benjamin's writings remind us, the question remains as to which mode of language and experience should be privileged. 
iii

To recognize the role that language plays in mediating our experience is to do more than add language to an assemblage of factors that might come into play within any social setting. If we take to heart what theorists like Walter Benjamin say, we find ourselves thinking about our lives differently from the way that standards-based reforms construct reality. It is simply impossible to posit a world as an object of knowing outside the context of the social relationships in which we collectively reproduce that world each day. Nor can we know the world outside the language that we use to act upon it. Language is always a sign of a shared world, inextricably bound up with our relations with one another and the activities in which we engage as we make the world anew each day. To borrow from Raymond Williams, 'language is the articulation of this active and changing experience; a dynamic and articulated social presence in the world' (Williams 1977, 21, 38). When policy makers and those academics they have coopted to do their work diminish the multifaceted role that language plays in our lives, reducing language to a set of literacy skills that individuals need in order to take their place in the economy, they undermine people's capacity for behaving sociably and indeed acting collectively to change the world.

The work of language educators is severely compromised by standards-based reforms, because those reforms require them to think about their work within an epistemological framework that is deeply at odds with the ways of knowing that lie at the heart of their practice as scholars and teachers. This was the starting point for the approach we made to language educators around the world to think about the way they construct and further develop their epistemology of practice in and through the situations in which they operate from day to day. We were working on the assumption that L1 teachers are mindful of the way that language mediates social relationships and experience, and our aim was to inquire into and make explicit the role that language plays in their professional learning, whether it be in the form of conversations with peers, reflective writing or by other means. In what follows we present excerpts from the abstracts of essays that we subsequently received from contributors. (We have not included the names of contributors, because some of these essays are still being reviewed.)

"I thought to myself: What a long way I've come..." - Teacher writing for professional growth (Israel)

The study on which this article is reporting explores the practice of professional writing and collegial dialogue as a means of learning, empowerment and professional renewal for Israeli educators. It shows multiple ways in which language from a professional learning context can connect with classroom practice ... language is seen as a powerful medium for thinking, talking and writing about professional experience.

L1 and L2 in teacher education: Teachers of Finnish L1 (F1) as teachers of Finnish L2 (F2): Challenges of multicultural competences (Finland)

A special case in the Finnish teacher education system: student teachers work in multicultural classes in the university's teacher training school, and teacher education has taken a number of initiatives to increase the understanding of co-operation, cultures and language learning and to provide skills for them. 
Writing in the literacy era: Nordic teachers' understanding of writing in Mother Tongue Education (Denmark)

This study is part of a larger Nordic research project, Nordfag.net, investigating Nordic mother tongue teachers' didactic profiles and conceptions of the Mother Tongue Education subject through an ethnographic approach. The background of the study is the general educational focus on literacy and language across the curriculum, changing traditional 'divisions of labour' among disciplines and raising questions as to the role of the MTE discipline in the teaching of writing. Teacher diaries and interviews are examined to find patterns in Nordic teachers' understanding of writing as part of their MTE teaching practice ... The article concludes that a tentative answer to the question of Mother Tongue Education writing may be found in some Nordic teachers' descriptions and reflections on their practice. In these, writing is understood and practised as an integral part of MTE teaching, aiming at supporting students' language and literary competence and reflection as well as their personal and social development. Inherent in this didactic project is the idea of Bildung, as well as teachers' positioning themselves as disciplinary didacticians with professional authority and autonomy.

Teachers' knowledge and wisdom - realized through language? (Norway)

The empirical foundation of the article is a case study of seven Icelandic L1 teachers. The article analyses the concept of teachers' professional knowledge ... The analysis indicates that the L1 subject in some respects is in a special position: in addition to being a school subject, it relates to cultural traditions and values. Moreover, the subject relates to pupils' development both as individuals and citizens, and so even deals with citizenship in a fundamental way. Furthermore, L1 is a tool for any subject: pupils need to read and to express themselves in writing and orally in all classes. Besides, the subject often treats themes which affect pupils personally, e.g. due to the close connection between language and identity. Therefore teachers' knowledge should include morality, in addition to academic and didactic skills.

Teachers' learning in a London school: Autonomy and development in the 1950s (England)

In the first two decades after the war L1 (English) teachers in Walworth School, an 'experimental' state secondary school in a working-class area of London, worked out, essentially by themselves, a common curriculum and pedagogy for the entire ability range of students. In developing their widely influential approach the teachers constituted themselves as a professional learning community, engaging equally in developing practice in a school and participating in the hopeful politics and culture of postwar Britain.

Writing reflective texts in teacher education: The construction of a didactic approach (The Netherlands)

In Teacher Education in the Netherlands there is a move towards a more school-based curriculum ... 'Practice' is just taken for granted but not discussed ... This form of 'practicum turn' is in line with a movement to see teachers as performers of formal curricula and controlled by educational outcomes. In contrast, we emphasize the importance of teachers being professionals who are accountable for their education, based on a critical scrutiny of their own practice, and their own beliefs on learning, teaching, education, the relation between education and society, the status of the teaching profession, etc. More emphasis on practice thus stresses the need for reflection on practice, using theory in order to critically analyze practice and developing alternative action. In this paper we describe the development of a didactic approach for learning how to reflect and to write reflective reports which could close this gap. 
Language education in the pre-school years. Learning about teachers' learning through an in-service programme (Portugal)

In this paper, I present and discuss some results of a research project that was carried throughout the implementation of an in-service programme specifically designed to help pre-school teachers improve their professional knowledge about language education. I briefly describe the political and institutional conditions that made it possible, outlining the theoretical foundations of the in-service programme and the training procedures followed. After introducing the research methodology, I present the general pattern of results (illustrated with the case of a teacher's portfolio), and some possible factors that influenced the learning are tentatively identified. The general idea is discussed that specific conceptual needs about language education as well as the general cognitive disposition seem to intersect to determine teachers' professional learning in this area.

Signs of construction of a professional Learning community in language education: A case study (Portugal)

The project 'Languages and Education: constructing and sharing professional knowledge' evolved around the development of a community-based environment organised in thematic working groups of teachers, educators and researchers. The research purpose was to study the construction of such a community, as well as the professional development trajectories of its members ... This investigation seeks to contribute to knowledge generation about professional learning communities in language education, and puts forward possible routes to follow-up networks or partnerships which may enhance and nurture the culture of collaboration initiated within the project.

A catalyst leading experienced primary teachers to change the ways they teach reading (Hong Kong)

This paper reports the impact on a small group of Taiwanese Chinese Language primary school teachers of a guided visit to Hong Kong to observe how the subject they were responsible for teaching was being taught in Hong Kong. The project was funded by a social enterprise in Taiwan and led by a Taiwanese academic working with assistance from Chinese Language specialists in the University of Hong Kong. Teachers from Hong Kong and Taiwan shared their professional experiences, and school visits were arranged for the Taiwanese teachers to see how reading comprehension was being taught in primary schools in Hong Kong.

The heterogeneity of these essays perhaps defies any effort to combine them within a single perspective. Yet they are all responses to the call for inquiry into the mediating role of language in professional learning; and the situated character of each essay might be read as a characteristic of inquiry with this kind of focus. This is despite the fact that nearly all the essays grapple with pressures towards uniformity that are named by words like 'globalization' and 'standards-based reforms' (or, indeed, acronyms like 'PISA' [Programme for International Student Assessment]), and the kind of stance towards language and literacy education implied by these words. Those pressures towards uniformity that the Danish educator gives to her essay, 'Writing in the literacy era', in which she captures the contradictory nature of her professional setting, where an emphasis on literacy teaching for purely vocational purposes conflicts with a larger vision of education expressed in the word 'Bildung'.

Words like 'Bildung' (used in the essays written by the Danish and Norwegian educators) are a reminder, not only of differences in the geographical locations of these writers but also of the distinctive cultural traditions that mediate their work as 
researchers and educators. 'Bildung' names a cluster of values and practices that do not easily translate from one language to another, as is shown by the fact that it is best to use this word without trying to offer an English equivalent. That the contributors to this special issue are all writing in English is in itself a sign of pressures towards globalization and standardization in conflict with their identities as speakers of other languages. But despite all these essays being published in English, their words signify worlds beyond English, traces of other cultures, other traditions of curriculum and pedagogy that cannot simply be collapsed together as examples of the same thing (cf. van de Ven and Doecke 2011).

Yet to foreground the specific character of each writer's reflections on professional learning, as he or she has observed it through implementing the various projects they describe, does not preclude the possibility of making generalizations. That would be to leave us trapped in immediacy, without any capacity to identify larger contexts or structures that mediate the phenomena of everyday life as it presents itself to us. Our point is that any general statement that we might make about the professional learning of language educators should be wary of a logic of sameness, as though we can make connections between different socio-cultural settings without any regard to the specific histories that have produced those settings, such as that which is most crudely evident in the fetish that is currently made of international comparisons (as with PISA). Although what these writers say about the professional learning of language educators has been rendered in the lingua franca of English, and they appear to share a common lexicon, the same word can mean different things, resonating with meanings that do not actually lend themselves to translation. Even when we seem to encounter common values - such as appears to be the case when the writers use the word 'professional' or invoke the notion of a 'professional learning community' - it is only possible to generalize in the most provisional way.

Having made this qualification, we can nonetheless identify in these essays an outline of an epistemology of practice, as it is enacted by language educators, that conflicts with the epistemological assumptions that typify the research underpinning standards-based reforms. From this epistemological standpoint it is simply crude to subject the complexities of language and learning to an analysis that fails to recognize the mediating role of language in human relations and the construction of knowledge. We see in these essays, for example, a valuing of knowledge as it might be constructed through talk, both as a focus for inquiry in classroom settings and as a means by which educators and researchers can conduct that inquiry, when they plan opportunities to share their experiences by engaging in conversation (Mercer 1995; Wells 1999; Barnes 1975/1992). Small group talk typically involves people speaking out of specific situations, and it often evokes scenes and events which, in their rich particularity, do not easily lend themselves to being classified. It is also noteworthy that such talk typically involves a privileging of storytelling as a vehicle through which to share experiences. The characters and settings in any narrative have an irreducible quality that resists generalization, even as we try to arrive at an understanding of the larger contexts that mediate the specific situation evoked by that story.

The epistemology of practice of the language educators who have contributed to this special issue of $L-1$ is characterized by a reflexivity arising from their sensitivity to the role that language plays in our lives. It might be said that a language educator is always disposed to stop to listen to his or her own words even as they are being spoken. As Terry Eagleton observes, there are moments when such a disposition can be debilitating, when it is necessary to respond immediately to whatever 
imperative is being directed at you, and take action without reflecting on the language in which that imperative has been couched $(2007,68)$. But just going ahead and getting things done, without pausing to reflect on the way language mediates everyday practice - as when student teachers are thrown into the hurly burly of teaching without any capacity to reflect on what they are doing (as Ietje Pauw and Piet-Hein van de Ven report is a growing trend in the Netherlands), or when teachers allow a capacity to think critically about their work to be crowded out by the routines associated with standardized testing - is not an appropriate disposition, if we wish to hold on to the value of inquiry as an integral part of our work as language educators. We need to cultivate a heightened sensitivity to language, whether it be to particular words that we are employing or the mood of a sentence or the pronouns that we are using. Such reflexivity is an indispensable condition for remaining fully aware of the implications of our work as language educators (cf. Doecke and Parr 2011).

iv

We remarked earlier that Walter Benjamin's work presents an alternative philosophical framework to that which is reflected in standards-based reforms. Our aim has been to highlight the fact that standards-based reforms themselves embody a worldview or ideology, and that Benjamin's work provides a means of dislodging ourselves from the common-sense assumptions that underpin them. Yet resistance to these reforms involves more than choosing a new world-view, as though you can steer your shopping trolley through the aisles of the Supermarket of Ideas, weighing up the value of this ontology or that epistemology in comparison with other products on offer. Such a notion of choice (often reflected in the way Research Methodology Handbooks showcase a range of methodologies available to research students) is symptomatic of the very situation that we need to critique. If Benjamin teaches us anything, it is to do with the complexity of anyone's socialization into a set of beliefs and values, into a certain way of knowing and acting within the world. This is not to say that his standpoint vis-à-vis the society into which he was born was fixed once and for all as a product of his upbringing - he draws a line between then and now, pondering his situation as an adult who has since learned to live without the security afforded him by his childhood. Yet the memories of his childhood persist, traces of his entry into the world, crucially bound up with the language he used in his interactions with the people and situations he encountered. And these experiences were far more than a matter of taking cognizance of an 'external' world, as though our relation to the world is primarily a matter of 'knowing' it. Benjamin describes the word games he played as a child, when 'Muhme Rehlen' became the 'Muhmerehlen', as leading to the heart of being ('die Wege, die in ihr Inneres fuehrten') (see Kramer 2003, 32), meaning his situation, not only vis-à-vis a world that might be posited as the object of a knowing subject, but the mystery of the presence of others and his burgeoning sense of his obligations towards them.

Benjamin's account of his own socialization as a child of the middle class in Germany at the turn of the century is remarkable for its sustained focus on his education as an educator. The latter phrase derives from the 'Theses on Feuerbach', where Marx posits the need for all would-be social reformers to interrogate their own circumstances and upbringing as a key to understanding why they have developed a socially critical stance vis-à-vis the world in which they find themselves 
(Marx 1969). Benjamin's writing is entirely within the spirit of the educational project that Marx outlines in his 'Theses on Feuerbach'. His work can be placed alongside the work of other exponents of a philosophy of 'praxis', such as Rosa Luxemburg, Antonio Gramsci, Paolo Freire, or Frigga Haug - writers who also conceive social reform as an educational project, involving a pedagogy that enables people to engage reflexively in the conditions of their own making and to seize the possibility of social change as conscious actors within history. This does not necessarily mean subscribing to the large-scale scenario for revolutionary change that shapes Marx's work, as though as language educators we can make direct connections between what occurs in our classrooms and wider movements for social reform. There is no escaping the obligation to think relationally, to understand how our work as language educators is mediated by larger social structures; but the starting point for such awareness has to be the here-and-now, as we negotiate the social relationships that constitute any classroom (cf. Doecke and McClenaghan 2011).

The starting point for such awareness is experience. We need to reclaim that word as naming what is at the heart of our work as language educators. This is not to specify a pre-defined content but to signify the form of our engagement with young people and our openness to all that they bring to their conversations with us. In this respect we might invoke other theorists whose work is in danger of being lost to us through the hegemony of standards-based reforms, along with the philosophers of 'praxis' that we have just mentioned. Dewey, Vygotsky, Bruner, Moffett, Barnes, Britton and Rosen - the work of all these writers might usefully be read alongside Benjamin's writing, all contributing to a heightened sense of the complex ways in which language and experience interweave.

But there is, after all, something to be said about the way the work of a theorist like Benjamin, and the cultural tradition in which his writing might be located, can dislodge us from the habits of thought and action that have become second nature to us because of the hegemony of standards. Our final point is as simple as that. Advocates of standards-based reforms in the Anglophone world typically dismiss any attempt to refocus on the legacy of educators like Britton, Barnes and Rosen as regressive (see, e.g., Christie et al. 1991, Christie 1993; cf. Reid 2003, 105; Goodwyn 2003; Doecke and McClenaghan 2011, 22, 41, 57), a lapse into a pedagogy that has long been superseded by other more scientifically grounded attempts to improve the educational 'outcomes' of students. Although significant work is being done to challenge this caricature (Medway, forthcoming; Gibbons 2009), those of us whose work has been shaped by Britton, Barnes, Rosen and their contemporaries inevitably struggle with such a construction of this intellectual tradition. Benjamin's work cannot be contained by the relentless waves of reform and pedagogical bandwagons that have been a feature of neo-liberalism because they are written from a standpoint that is completely outside this world, a standpoint from which these recipes for 'improving' educational outcomes can only be judged to be intellectually bankrupt.

Yet, as we have just observed, the issue is not, finally, resolved by privileging one world-view or ideology over another, but by following Benjamin's example and that of other writers and educators who have likewise attempted to focus squarely on experience and to grapple with the mystery of life as it presented itself to them. There is no denying that mystery - just as there is no denying that any education worthy of the name should have that mystery as its inspiration and focus. Benjamin's writings convey a deep respect for the world of children as they experience it, reflected in his acknowledgment of the complexity of their attempts to 
know and operate within it. His writings encourage us, as educators, to revisit the conditions for our own initial engagement with the world around us. This is not only a matter of allowing young people to be young people, attending to what we can learn from them about their experiences, rather than imposing on them the seriousness and grimness and drudgery that supposedly befit an adult world. We should also be prompted to consider how as teachers we might remain responsive to the world around us, attending to the ways our own subjectivities are shaped by our experiences from day to day, and how the discourse of standards-based reforms is mediating what we think and do. We started this essay by foregrounding that discourse and the potential it has to silence the voices of young people. We shall conclude by affirming the need for teachers to find their voices, too. In this respect, we are optimistic. The contributors to the special issue of $L-1$ that we have edited have taught us that teachers' inquiry into their experiences as educators is continuing, despite the pressures by governments to close down free and independent inquiry and to deny the legitimacy of dissent.

\section{Notes on contributors}

Brenton Doecke is a Professor in the School of Education at Deakin University, Australia. $\mathrm{He}$ has written extensively on English curriculum and pedagogy. His most recent publications include a co-authored book with Douglas McClenaghan, Confronting Practice: Classroom Investigations into Language and Learning (Putney, Australia: Phoenix Education, 2011) and an edited collection of essays with Piet-Hein van de Ven, entitled Literary Praxis: A Conversational Inquiry into the Teaching of Literature (Rotterdam: Sense, 2011). With Iris Pereira, he has co-edited a special issue of L-1: Educational Studies in Language and Literature: 'The Inescapability of Language: Theory and Practice for L-1 Educators' (forthcoming).

Iris Susana Pires Pereira teaches in the Institute of Education at the University of Minho, Portugal. Her main research areas include literacy education in the pre-school and primary years and teacher professional learning. She has published 'The Teaching of Portuguese in the Primary and Late Primary School Years. Professional knowledge construction in the context of PNEP and the new official program' (in Portuguese). Together with Brenton Doecke, she is the guest editor of the special issue of L-1: Educational Studies in Language and Literature: 'The Inescapability of Language: Theory and Practice for L-1 Educators' (forthcoming).

\section{References}

Barnes, D. 1975/1992. From Communication to Curriculum. 2nd ed. Portsmouth, NH: Boynton/Cook.

Beasley-Murray, T. 2007. Mikhail Bakhtin and Walter Benjamin: Experience and Form. Basingstoke, UK: Palgrave Macmillan.

Benjamin, W. 1928/1955. Einbahnstrasse. Frankfurt am Main, Germany: Suhrkamp Verlag.

Benjamin, W. 1973. Understanding Brecht. Trans. Anna Bostok. London: NLB.

Benjamin, W. 1996/2004. Selected Writings. Vol. 1, 1913-1926. Ed. Marcus Bullock and Michael W. Jennings. Cambridge, MA: The Belknap Press of Harvard University Press.

Benjamin, W. 2002. Selected Writings. Vol. 3, 1935-1938. Trans. Edmund Jephcott and others. Ed. Howard Eiland and Michael W. Jennings. Cambridge, MA: The Belknap Press of Harvard University Press.

Bita, N. 2009. Testing foes want happy, uneducated kids: Gillard. The Australian, November 13. $\mathrm{http} / /$ www.theaustralian.com.au/news/nation/testing-foes-want-happy-uneducated-kids-gillar d/story-e6frg6nf-1225797124314.

Christie, F. 1993. The 'Received Tradition' of English Teaching: The Decline of Rhetoric and the Corruption of Grammar. In The Insistence of the Letter: Literacy Studies and Curriculum Theorizing, ed. B. Green, 75-106. London: Falmer Press. 
Christie, F., B. Devlin, P. Freebody, A. Luke, J. Martin, T., Threadgold, and C. Walton. 1991. Teaching English Literacy: A Project of National Significance on the Preservice Preparation of Teachers for Teaching English Literacy. Report presented by Frances Christie, Project Chair, to John Dawkins, Minister of Employment, Education and Training, August 31. http://catalogue.nla.gov.au/Record/2726373.

Comber, B., and P. Cormack. 2011. Education Policy Mediation: Principals' Work with Mandated Literacy Assessment. English in Australia 46, no. 2: 77-86.

Critchley, S. 1992/1999. The Ethics of Deconstruction: Derrida and Levinas. Edinburgh: Edinburgh University Press.

Darling-Hammond, L. 2004. Standards, Accountability, and School Reform. Teachers College Record 106, no. 6: 1047-85.

Doecke, B., A. Kostogriz, and B. Illesca. 2010. Seeing 'things' differently: recognition, ethics, praxis. English Teaching: Practice and Critique 9, no. 2: 81-98.

Doecke, B., and D. McClenaghan. 2011. Confronting Practice: Classroom Investigations into Language and Learning. Putney, Australia: Phoenix Education.

Doecke, B., and G. Parr. 2011. The National Mapping of Teacher Professional Learning project: A multi-dimensional space? English in Australia 46, no. 2: 9-20.

Eagleton, T. 2007. How to Read a Poem. Oxford: Blackwell.

Gibbons, S. 2009. Lessons from the Past? English Teaching: Practice and Critique 8, no. 1: 64-75. http://education.waikato.ac.nz/research/files/etpc/files/2009v8n1 art4.pdf.

Goodwyn, A. 2003. 'We Teach English Not Literacy': 'Growth' Pedagogy Under Siege in England. In English Teachers at Work: Narratives, Counternarratives and Arguments, ed. B. Doecke, D. Homer, and H. Nixon, 123-34. Kent Town, Australia: Wakefield Press.

Hopkins, D., J. Munro, and W. Craig. 2011. Powerful Learning: A Strategy for Educational Improvement. Camberwell, Australia: ACER Press.

Koretz, D. 2008. Measuring Up: What Educational Testing Really Tells Us. Cambridge, MA: Harvard University Press.

Kramer, S. 2003. Walter Benjamin zur Einführung. Hamburg: Junius.

Leslie, E. 2007. Walter Benjamin. London: Reaktion Books.

Levinas, E. 1981/2004. Otherwise than Being: Or Beyond Essence. Trans. A. Lingis. Pittsburgh, PA: Duquesne University Press.

Marx, K. 1969. Theses on Feuerbach. In Selected Works, Vol. 1. K. Marx and F. Engels. Moscow: Moscow Progress.

McGaw, B. 2011. Foreword. In Powerful Learning: A Strategy for Educational Improvement, D. Hopkins, J. Munro, and W. Craig, vii-viii. Camberwell, Australia: ACER Press.

Medway, P. Forthcoming. Teachers' learning in a London school: autonomy and development in the 1950s. L-1: Educational Studies in Language and Literature.

Mercer, C. 1995. The Guided Construction of Knowledge: Talk amongst teachers and learners. Clevedon, UK: Multilingual Matters.

Ministerial Council on Education, Employment, Training and Youth Affairs (MCEETYA). 2008. Melbourne Declaration on Educational Goals for Young Australians. http://www. mceecdya.edu.au/mceecdya/melbourne_declaration,25979.html.

Reid, I. 2003. The Persistent Pedagogy of 'Growth'. In English Teachers at Work: Narratives, Counternarratives and Arguments, ed. B. Doecke, D. Homer, and H. Nixon, 97108. Kent Town, Australia: Wakefield Press.

van de Ven, P.-H., and B. Doecke, eds. 2011. Literary Praxis: A Conversational Inquiry into the Teaching of Literature. Rotterdam: Sense.

Wells, G. 1999. Dialogic Inquiry: Towards a Sociocultural Practice and Theory of Education. Cambridge: Cambridge University Press.

Williams, R. 1977. Marxism and Literature. Oxford: Oxford University Press. 